\title{
Green synthesis and antibacterial effects of aqueous colloidal solutions of silver nanoparticles using camomile terpenoids as a combined reducing and capping agent
}

\author{
Magdalena Parlinska-Wojtan ${ }^{1}$ Małgorzata Kus-Liskiewicz ${ }^{2} \cdot$ Joanna Depciuch $^{1}$ • \\ Omowunmi Sadik ${ }^{3}$
}

Received: 2 January 2016/Accepted: 24 March 2016/Published online: 15 April 2016

(c) The Author(s) 2016. This article is published with open access at Springerlink.com

\begin{abstract}
Green synthesis method using camomile extract was applied to synthesize silver nanoparticles to tune their antibacterial properties merging the synergistic effect of camomile and $\mathrm{Ag}$. Scanning transmission electron microscopy revealed that camomile extract (CE) consisted of porous globular nanometer sized structures, which were a perfect support for Ag nanoparticles. The Ag nanoparticles synthesized with the camomile extract (AgNPs/CE) of $7 \mathrm{~nm}$ average sizes, were uniformly distributed on the CE support, contrary to the pure Ag nanoparticles synthesized with glucose $(\mathrm{AgNPs} / \mathrm{G})$, which were over $50 \mathrm{~nm}$ in diameter and strongly agglomerated. The energy dispersive $\mathrm{X}$-ray spectroscopy chemical analysis showed that camomile terpenoids act as a capping and reducing agent being adsorbed on the surface of AgNPs/CE enabling their reduction from $\mathrm{Ag}^{+}$and preventing them from agglomeration. Fourier transform infrared and ultraviolet-visible spectroscopy measurements confirmed these findings, as the spectra of $\mathrm{AgNPs} / \mathrm{CE}$, compared to pure $\mathrm{CE}$, did not contain the $1109 \mathrm{~cm}^{-1}$ band, corresponding to $-\mathrm{C}-\mathrm{O}$ groups of terpenoids and the peaks at 280 and $320 \mathrm{~nm}$, respectively. Antibacterial tests using four bacteria strains showed that the AgNPs/CE performed five times better
\end{abstract}

Magdalena Parlinska-Wojtan

bpparlin@cyf-kr.edu.pl; magdalena.parlinska@ifj.edu.pl

1 Institute of Nuclear Physics, Polish Academy of Sciences, 31342 Kraków, Poland

2 Biotechnology Centre for Applied and Fundamental Sciences, Department of Biotechnology, University of Rzeszow, Sokołowska Street 26, 36-100 Kolbuszowa, Poland

3 Department of Chemistry, State University of New York at Binghamton, Binghamton, NY 13902, USA compared to CE AgNPs/G samples, reducing totally all the bacteria in $2 \mathrm{~h}$.

Keywords Green synthesis - Silver nanoparticles · Camomile $\cdot$ Antibacterial properties

\section{Introduction}

Nanoscience allows fabricating particles with diameters between 1 and $100 \mathrm{~nm}$ [1], which can be used in materials science, chemistry, medicine or biology. In the two latter segments, one of the most popular nanoparticles (NPs) is silver particles [2], as they show great antibacterial and anticancer activities [3-7]. The unique properties of these nanoparticles are determined by their small size (1-100 nm), but also their shape, structure and surface functionality [8]. Various manufacturing methods of silver nanoparticles are known, but most of them are harmful for the environment, because they require the use of heavy and toxic chemicals, which are necessary in chemical and photochemical reactions and microwave assisted processes [9-11]. Green synthesis involves a set of principles to reduce or eliminate the use or generation of hazardous substances in the design, manufacture and application of silver nanoparticles [12, 13]. Thus, synthesis methods based on the use of plant extracts [13] to synthesize the silver nanoparticles from silver nitrate are of great interest.

The use of plant parts and isolated phytochemicals for the prevention and treatment of various health disorders has been in practice for many decades. For the treatments, bioactive components from medicinal plants, which are similar to chemical compounds, are used [14, 15]. Extracts of plants, used in green synthesis, include active molecules acting as reducing and capping agents such as flavonoids, 
tannins, amines, aldehyde/ketone groups and polyols and proteins for $\mathrm{Ag}^{+}$[16-18]. Syntheses of silver nanoparticles using black pepper leaf extract [19], olive leafs [20], cinnamon barks [21], grape seed extract [22], or papaya fruit extract [23] have been reported.

Many studies have described the beneficial properties of camomile herb (Matricaria camomilia), which is one of the oldest and the most popular plants used in medicine [24, 25]. Camomile has been used to treat various inflammations, wounds, neuralgia, ulcers and rheumatic pains [26, 27] or as mouthwash to treat gingivae [28]. Moreover, the extract of camomile inhibits the growth of human cancer cells [29]. The therapeutic activity of camomile is due to different effective substances such as phenolics and flavonoids apigenin, quercetin, patuletin, luteolin, and their glucosides. Other compounds in camomile include: sesquiterpenes, terpenoids, flavonoids, coumarins such as herniarin and umbelliferone, phenylpropanoids such as chlorogenic acid and caffeic acid.

The aim of this study is to eliminate heavy chemicals in the design and manufacture of silver nanoparticles (AgNPs) from aqueous extracts of camomile for antimicrobial applications. In addition, by synthesizing in camomile extract it is expected to achieve a synergistic cytotoxic effect. These green-synthesized silver nanoparticles in camomile extract (AgNPs/CE) were examined by scanning transmission electron microscopy (STEM), energy dispersive X-ray analysis (EDX), Fourier transform infrared spectroscopy (FTIR) and UV-vis to determine, which compound of camomile reduces $\mathrm{Ag}^{+}$ions into $\mathrm{Ag}$ nanoparticles. The cytotoxic effect of AgNPs/CE was analyzed by the percentage of reduction, the zone of inhibition and the minimum inhibitory concentration on four different bacteria strains, and the results were compared to conventionally synthesized Ag NPs.

\section{Experimental}

\section{Synthesis of AgNPs}

Silver (I) nitrate $(\mathrm{AgNO} 3, \geq 99.0 \%)$ and glucose $\left(\mathrm{C}_{6} \mathrm{H}_{12} \mathrm{O}_{6}\right.$ $\geq 99.5 \%$ ) were purchased from Sigma-Aldrich, Poland. The silver nanoparticles were directly synthesized in the camomile extract via a simple green synthesis procedure. The camomile extract was prepared by mixing $500 \mathrm{ml}$ of deionized water and $100 \mathrm{~g}$ of dried camomile flowers and keeping the obtained slurry at $90{ }^{\circ} \mathrm{C}$ for $5 \mathrm{~h}$ without boiling. After cooling, the extract was filtered using filter paper. Next, $5 \mathrm{ml}$ of the flower extract was mixed at room temperature with $500 \mathrm{ml}$ of silver nitrate solution (1 mmol). The obtained mixture was kept undisturbed in a dark place. With time, the color of the solution changed into a reddish-brown, which was associated with the formation of silver nanoparticles. Finally, the NPs were collected by centrifugation. The concentration of the used camomile extract was $0.167 \mathrm{mg}$ camomile extract/1 ml. As the synthesis of AgNPs/CE was successful at room temperature, further effects of camomile extract concentration or the influence of temperature on the formation of $\mathrm{Ag}$ nanoparticles were not performed.

The pure (without any plant extracts) Ag nanoparticles, used as a reference sample to evaluate the antibacterial properties of the camomile synthesized silver NPs, were synthesized using the following procedure. $50 \mathrm{ml}$ of glucose solution $(0.03 \mathrm{M})$ was mixed with $100 \mu \mathrm{l}$ of silver nitrate $(0.15 \mathrm{M})$ at room temperature. Subsequently, it was kept undisturbed in dark place for $2 \mathrm{~h}$ until it changed the color to gray. To simplify further sample nomenclature, the initial concentration of silver nitrate in AgNPs/CE $(300 \mu \mathrm{M})$ was used to estimate the concentrations for minimum inhibitory concentration (MICs) evaluation.

\section{Structural characterization}

The structure of the pure camomile extract (CE), camomile extract with silver nanoparticles (AgNPs/CE) and pure silver nanoparticles synthesized with glucose (AgNPs/G) were analyzed by transmission electron microscopy (TEM). A drop of each suspension was deposited on a TEM Cu grid coated with a carbon foil, and subsequently dried. The sample was observed in the scanning transmission electron microscopy (STEM) mode using the high angular annular dark field (HAADF) detector on a FEI Tecnai Osiris operating at $200 \mathrm{kV}$ with a resolution of $0.15 \mathrm{~nm}$ in STEM. The FEG instrument is equipped with a unique in-column EDX system allowing for fast acquiring of EDX maps of the sample.

\section{Infrared spectroscopy measurements}

The FTIR spectroscopy measurements were performed using the Vertex 70 (Bruker) spectrometer employing the attenuated total reflectance (ATR) technique; a diamond crystal was applied for this purpose. All the analyses were performed in the average IR range, more precisely, between 400 and $3500 \mathrm{~cm}^{-1}$ wavelength. 64 scans were used to obtain a spectral resolution of $4 \mathrm{~cm}^{-1}$.

\section{UV-vis}

The UV-vis measurements were performed with an evolution 3000 instrument from Thermo Scientific for all three suspensions. The resolution was chosen to be $2 \mathrm{~nm}$ and the scan speed was $240 \mathrm{~nm} / \mathrm{min}$. The spectral range was from 250 to $900 \mathrm{~nm}$. 


\section{Particle size measurements}

The particle size measurements were performed using a Zetasizer Nano ZS instrument from Malvern. Dynamic light scattering (DLS) technique is used to measure the particle size. The measurements were performed at room temperature $\left(25^{\circ} \mathrm{C}\right)$ using red laser $(633 \mathrm{~nm}, 4 \mathrm{~mW})$ and the measurement angle was set at $173^{\circ}$.

\section{Antibacterial properties}

\section{Bacterial strains and cultures medium}

Four bacteria strains were employed to evaluate the potential of antibacterial activity of green synthesized silver nanoparticles. Gram-positive (Staphylococcus aureus ATCC 25923, Bacillus subtillis PCM 486) and gram-negative (Pseudomonas aeruginosa ATCC 27853, Escherichia coli PCM 2209) bacteria were studied. Nutrient broth (NB) or nutrient agar (NA) was used for the preparation of bacterial cultures suspension or evaluation of the colony forming unit (CFU), respectively. All media were purchased from the BTL Company (Poland). For serial dilutions phosphate buffered saline $(1 \times \mathrm{PBS} ; 137 \mathrm{mM} \mathrm{NaCl}$,

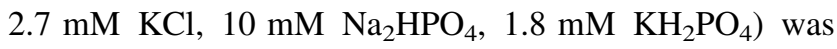
used.

\section{Antibacterial properties}

The camomile extract (CE), camomile extract synthesized silver nanoparticles (AgNPs/CE) and pure silver nanoparticles synthesized with glucose (AgNPs/G), were tested for their antibacterial activity. Three different experiments were conducted: (1) percentage of reduction, (2) zone of inhibition and (3) minimum inhibitory concentration (MIC) of tested strains according to the standard protocols Clinical and Laboratory Standards Institute (CSLI ), 2012. The bacteria cultures were prepared in $10 \mathrm{ml}$ of NB followed by overnight shaking at $37{ }^{\circ} \mathrm{C}$. (1) The initial inhibitory effects on the growth of microorganisms were tested against the $S$. aureus strain. After the exposure to the tested nanosuspensions (CE, AgNPs/CE and AgNPs), the bacteria colonies were counted and the $\mathrm{CFU} / \mathrm{ml}$ was estimated (the flowchart on Fig. 5c). Before the experiment, the density of the overnight inoculum was estimated and diluted to absorbance of $0.1 \mathrm{OD}_{600}$, which corresponds to $10^{6}$ cells/ $\mathrm{ml}$. Each of the tested microorganisms was mixed (in a ratio 1:9) with the $\mathrm{CE}$, with $\mathrm{AgNPs} / \mathrm{CE}$ and with $\mathrm{AgNPs} / \mathrm{G}$, and subsequently incubated at $37^{\circ} \mathrm{C}$ with shaking. The sampling time for the experiment was 0,4 and $24 \mathrm{~h}$. After the exposure period, bacteria colonies were counted and CFU were calculated. In the next step, the percentage of reduction $(\% R)$ in the growth of bacteria was estimated, however, in a shorter time regime. Samples were plated in triplicate, and the counts on the three plates were averaged. The inactivation efficiency $(\% R)$ was calculated according to formula:

$\% R=\left(\frac{\mathrm{CFU}_{\text {control }}-\mathrm{CFU}_{\text {sample }}}{\mathrm{CFU}_{\text {control }}}\right) \times 100 \%$.

(2) The zones of inhibition were measured according to a modified standard protocol [30]. This modification consisted in punching 5-mm diameter wells in the nutrient agar instead of using a soaked disc. This modification is motivated by the difference in the diffusion rate of the substances through the agar. The latter one depends on the depth, as well as on the molecular weight of the substances. $100 \mu \mathrm{l}\left(10^{8} \mathrm{CFU} / \mathrm{ml}\right)$ of bacterial suspension was spread onto the agar plates. When dried, $50 \mu \mathrm{l}$ of AgNPs/CE or pure AgNPs/G were aseptically transferred into separate wells. The plates were incubated at $37^{\circ} \mathrm{C}$ for $24 \mathrm{~h}$ and the average diameter of the inhibition zone surrounding the wells was measured. All tests were done in triplicate; the mean and standard deviations were estimated. (3) The broth microdilution method was used to determine the lowest concentration of the tested camomile and silver NPs containing solutions. The MIC assay was done according to the standard protocols [30] and previously cited in [31, 32]. Four tested strains were grown overnight on nutrient broth, and then were diluted to match the absorbance $\sim 0.1$ $\left(\mathrm{OD}_{600}\right.$, TECAN spectrophotometer), which corresponds to $1.5 \times 10^{6} .100 \mu \mathrm{l}$ of cells suspensions were distributed to the 96-well microtiter plate. Two of the tested nanosuspensions, AgNPs/CE and AgNPs/G, were diluted, and $100 \mu \mathrm{l}$ of each dilution were added to the wells containing bacterial cells. The negative (pure medium) and positive (pure medium with bacteria) controls were maintained. The microtiter plates were incubated for $24 \mathrm{~h}$ at $37{ }^{\circ} \mathrm{C}$ with shaking (250 rpm). The lowest concentration of the tested nanosuspensions, which was transparent, was considered as the MIC.

\section{Results}

\section{Particle size distribution}

Global information about the particle size distribution of the AgNPs/CE was obtained from the DLS measurements shown in Fig. 1. Two peaks are visible, showing an average particle size of 8 and $35 \mathrm{~nm}$, respectively. The peak at $8 \mathrm{~nm}$ is much more intense reaching $66.4 \%$ compared to the $35 \mathrm{~nm}$ peak at $33.6 \%$. To explain the nature of the particles generating these two peaks, transmission electron microscopy was applied to have more detailed local and structural information. 
Fig. 1 DLS spectrum of size distribution by number for $\mathrm{Ag}$ nanoparticles synthesized in the camomile extract

\section{Size Distribution by Number}

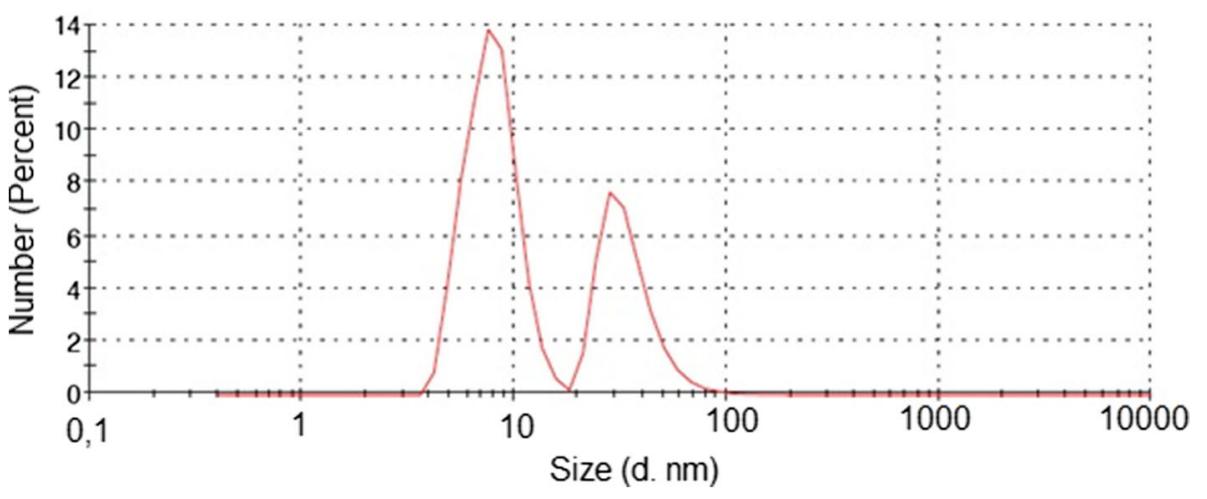

\section{Structural characterization}

Thus, the structures of the CE, the AgNPs/CE and AgNPs/ $\mathrm{G}$ were imaged by electron microscopy. Figure 2 presents the combination of STEM HAADF images with the corresponding quantified EDX maps of pure camomile extract (column I), Ag particles synthesized in the camomile extract (column II) and pure Ag particles synthesized with glucose (column III). The camomile extract consists of globular structures, which are agglomerated forming porous aggregates and networks. The spherical globules have sizes varying from approximately 20 to $70 \mathrm{~nm}$, Fig. 2a, b, what explains the presence of the DLS peak at $35 \mathrm{~nm}$ average particle size, Fig. 1. In the quantified EDX maps of the camomile extract the distribution of phosphorus and oxygen is shown, Fig. 2c, d. Phosphorus is an element present in terpenoids, Fig. $2 \mathrm{~m}$, a component of camomile. In the AgNPs/CE sample, column II in Fig. 2, the HAADF STEM images showed Ag particles uniformly distributed on the camomile globules. In the overview and the magnified images, Fig. 2e, f, respectively, the camomile extract is visible as a light gray contrast in between the $\mathrm{Ag}$ nanoparticles, however, the globules are more agglomerated then in pure camomile extract. The Ag particle size scattering is relatively large reaching from 2 to $25 \mathrm{~nm}$, what corresponds to the average particle size of $8 \mathrm{~nm}$ measured by DLS, Fig. 1. The quantified EDX maps clearly show the presence of Ag, oxygen and phosphorus originating from the camomile extract. Interestingly, phosphorus is not anymore detected on the camomile globules, but rather on the AgNPs. The structure of $\mathrm{Ag}$ nanoparticles synthesized without camomile extract is presented in the overview and the larger magnification images in column III, Fig. 2i, j, respectively. Due to the same scale bar it can be clearly seen that the AgNPs/G synthesized without camomile are much more agglomerated and much larger compared to AgNPs/CE. The
Fig. 2 STEM HAADF image with the corresponding EDX maps of I pure camomile extract used for the synthesis; II Ag particles synthesized in the camomile extract; III Ag particles synthesized with glucose; $\mathrm{M}$ chemical formula of terpenoids showing the presence of phosphorus

quantified contents in at. \% of oxygen, phosphorus, carbon and silver for the $\mathrm{CE}$ and AgNPs/CE samples are given in Table 1.

Figure 3a shows the FTIR spectrum of pure camomile extract CE. The band between 3410 and $3370 \mathrm{~cm}^{-1}$ matches the $\mathrm{O}-\mathrm{H}$ stretching in hydroxyl groups corresponding to phenol, and the $\mathrm{N}-\mathrm{H}$ stretching corresponds to amides. The peaks between 2920 and $2850 \mathrm{~cm}^{-1}$ are characteristic for the $\mathrm{C}-\mathrm{H}$ vibration (stretching) of aliphatic groups from glucosides. The band between 1750 and $1620 \mathrm{~cm}^{-1}$ corresponds to the $\mathrm{C}=\mathrm{O}$ vibration of bonded, conjugated esters from luteolin. The band at approximately $1640 \mathrm{~cm}^{-1}$ is attributed to the $\mathrm{C}=\mathrm{C}$ vibration of the aromatic chain in carboxylic acids probably from patulin. The peak around $1320-1370 \mathrm{~cm}^{-1}$ originates from the $\mathrm{C}-\mathrm{N}$ stretch vibration of the aromatic amine I and amine II. The band around $1250 \mathrm{~cm}^{-1}$ corresponds to $\mathrm{C}-\mathrm{H}$ stretching and $\mathrm{O}-\mathrm{H}$ deformation of carboxyl groups and to the $\mathrm{N}-\mathrm{H}$ bond of amide II. The peak at $1109 \mathrm{~cm}^{-1}$ is attributed to the $-\mathrm{C}-\mathrm{O}$ group of terpenoids [33]. The broad band centered around $1050 \mathrm{~cm}^{-1}$ is attributed to aromatic ethers and polysaccharides (C-O-C stretching). The bands at $900-600 \mathrm{~cm}^{-1}$ correspond to primary and secondary amines and amides [34]. The FTIR spectrum of AgNPs/CE nanoparticles, compared to pure $\mathrm{CE}$, does not contain the band at $1109 \mathrm{~cm}^{-1}$, which corresponds to $-\mathrm{C}-\mathrm{O}$ groups of polyols such as flavones, terpenoids and polysaccharides, Fig. 3b. These polyols are mainly responsible for the reduction of silver ions [35]. Figure $3 \mathrm{c}$ shows the FTIR spectrum of AgNPs/G synthesized by $\mathrm{Ag}^{+}$reduction with glucose. The vibrational spectra can be divided into two main groups of 
(I)
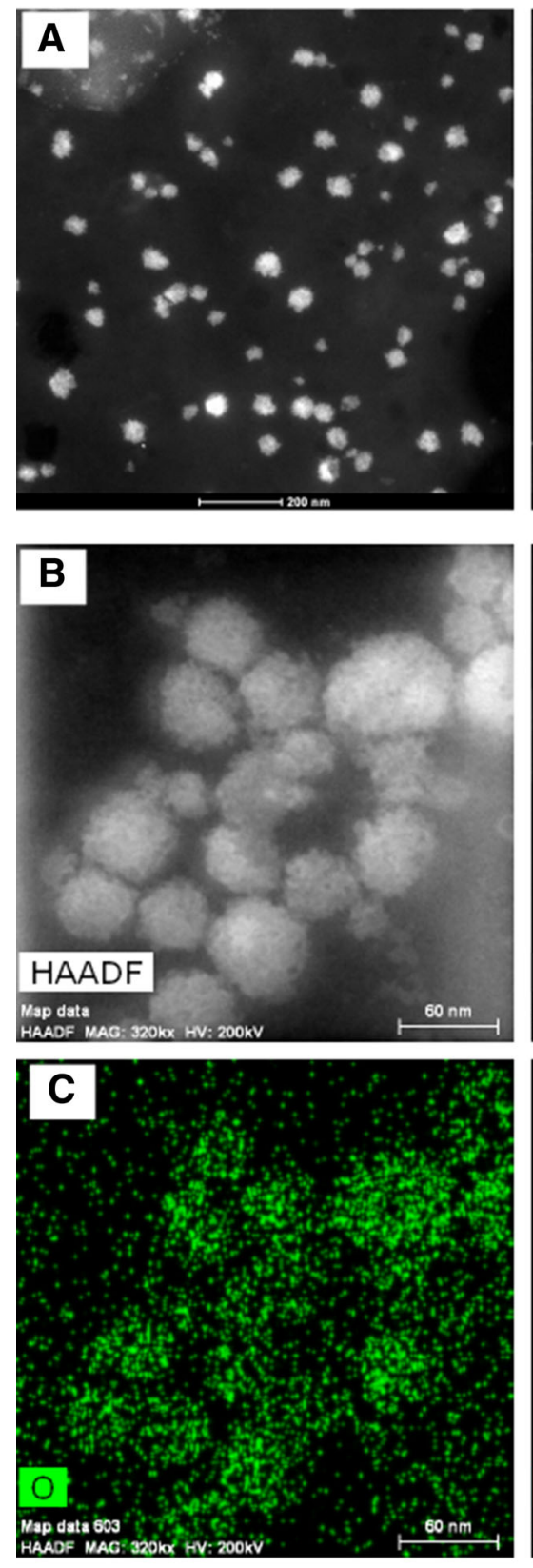

(II)
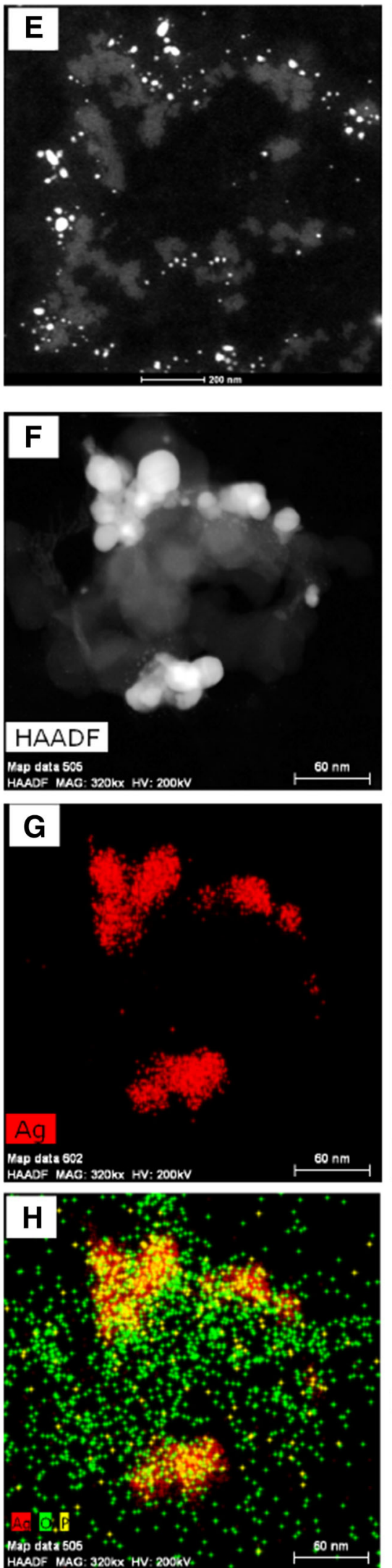

(III)
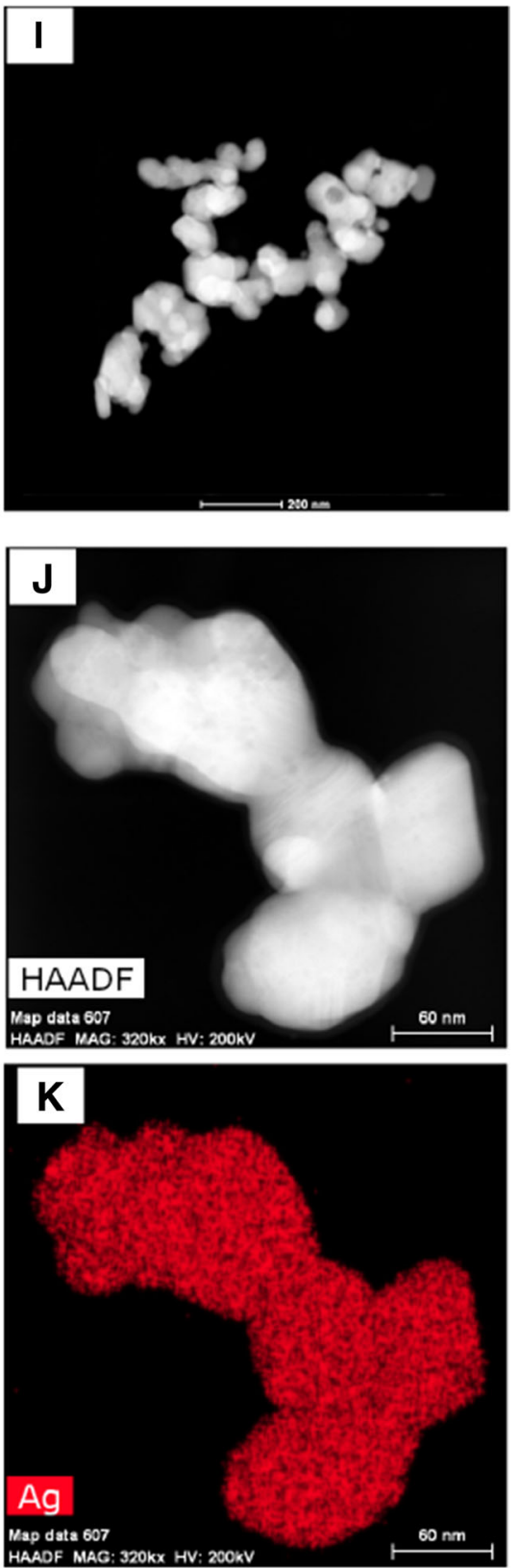

M<smiles>C=C(C)CCOP(=O)([O-])OP(=O)([O-])[O-]</smiles>

chemical formula of terpenoids present in camomile 
Table 1 Quantified contents estimated by EDX of oxygen, phosphorus, carbon and silver for the CE and AgNPs/CE samples

\begin{tabular}{lllll}
\hline & $\mathrm{O}($ at $\%)$ & $\mathrm{C}(\mathrm{at} \%)$ & $\mathrm{P}($ at $\%)$ & $\mathrm{Ag}($ at $\%)$ \\
\hline $\mathrm{CE}$ & 31.5 & 64.7 & 3.9 & - \\
$\mathrm{AgNPs} / \mathrm{CE}$ & 7.2 & 69 & 1.4 & 22.5 \\
\hline
\end{tabular}

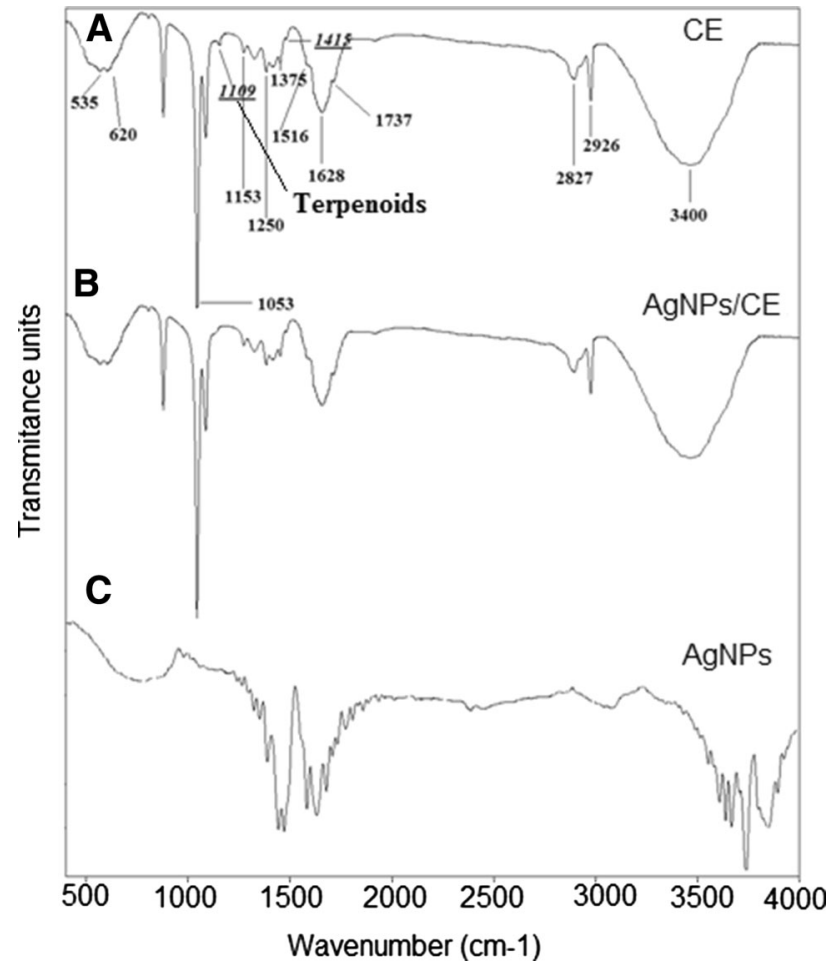

Fig. 3 Typical FTIR absorption spectra of: $a$ pure camomile extract $\mathrm{CE}$ and $b$ camomile extract synthesized silver nanoparticles AgNPs/ $\mathrm{CE}, c$ AgNPs/G synthesized by the $\mathrm{Ag}^{+}$reduction with glucose

peaks. The region from 1000 to $1700 \mathrm{~cm}^{-1}$ where $\mathrm{C}-\mathrm{O}$ and $\mathrm{C}-\mathrm{C}$ groups vibration modes are present and the carbohydrates generally show their characteristic bands. The second region contains bands from 2900 to $3450 \mathrm{~cm}^{-1}$ assigned to $\mathrm{CH}$ and $\mathrm{OH}$ vibrations groups [36]. All these peaks are summarized in Table 2.

Figure 4 shows the UV-vis spectra of the CE (black), AgNPs/CE (red) and AgNPs (green) suspensions. On the spectrum of CE two peaks are present at 280 and $320 \mathrm{~nm}$ corresponding to terpenoid [37-40]. These peaks disappear in the spectra measured for $\mathrm{AgNPs} / \mathrm{CE}$ and AgNPs/G. For these suspensions peaks at $425 \mathrm{~nm}$ originating from $\mathrm{Ag}$ nanoparticles are observed [41].

\section{Antibacterial properties}

The antibacterial impact of the camomile synthesized $\mathrm{Ag}$ nanoparticles was assessed. A comparison between the antibacterial properties of pure camomile extract, pure silver particles and Ag particles synthesized in the camomile extract was performed according to the CLSI protocol. This experiment showed that the CE sample has little bacteriostatic effect $(0.26 \mathrm{log}$ reduction after $4 \mathrm{~h}$ exposure). Further, cultivation does not show any inhibition of the bacteria growth (Fig. 5a), on the contrary, after a longer incubation time, increasing of the number of bacteria was observed. Conversely, total inhibition of bacteria growth was observed after exposure of cells to both silver containing nanosuspensions, regardless the incubation time.

Figure $5 \mathrm{~b}$ shows the inactivation efficiency for the two different nanosuspensions. Using different concentrations of the nanomaterial suspensions, different cell responses are observed. Pure silver nanoparticles show weaker degree of bacteria inhibition, especially, when comparing tenfold or hundredfold suspension dilution (upper part of Fig. 5b). The maximum percentage of reduction is 17.9 and $8.1 \%$ for tenfold or hundredfold diluted $\mathrm{AgNPs} / \mathrm{G}$, respectively. Only concentrated AgNPs/G exhibit a strong inhibition effect on the growth of $S$. aureus, as a $100 \%$ reduction is observed after $2 \mathrm{~h}$ of incubation. On the contrary, the nanosolution of $\mathrm{AgNPs} / \mathrm{CE}$, is much more antibacterial (bottom part of Fig. 5c). All tested concentrations have an impact on the bacteria growth: a total reduction of the bacteria after $2 \mathrm{~h}$ of exposure to all types of nanosuspensions, is observed. Summarizing, the antibacterial study shows that AgNPs/CE has excellent activity against $S$. aureus. The bacterial growth was limited for all AgNPs/CE samples, independently on their concentration.

We have extended our studies to the evaluation of the nanosolutions impact on different bacterial strains. It was estimated based on the zone of inhibition test. The obtained results of qualitative antibacterial diffusion tests, Fig. 6, showed that AgNPs/CE have an effect on all tested microorganisms, gram-positive and negative. The diameters of the average inhibition zones were $3.85,3.25,3.25$ and $2.94 \mathrm{~mm}$ for S. aureus, P. aeruginosa, B. subtilis and E. coli, respectively. For the AgNPs/G nanosolution, no inhibition was observed; only a $1 \mathrm{~mm}$ zone was detected for $S$. aureus.

To confirm the antibacterial activity of green-synthesized Ag nanoparticles, we defined the minimum inhibitory concentration (MIC) for the two gram-positive and two gramnegative bacteria, which was defined as the lowest concentration of $\mathrm{AgNPs} / \mathrm{CE}$, at which the strain cannot produce visible growth after overnight culturing. The results, showed that silver nanoparticles synthesized with camomile extract exhibit a high antibacterial activity, Fig. 7. These materials have the MICs for four strains ranging from 20 to $50 \mu \mathrm{M}$. Staphylococcus aureus was found as the most sensitive strain, and was able to growth only when exposed to $20 \mu \mathrm{M}$ of AgNPs/CE, while E. coli seems to be the most resistant after exposure to AgNPs/CE with MIC of $50 \mu \mathrm{M}$. 
Table 2 FTIR analysis of camomile extract and AgNPs/CE

\begin{tabular}{|c|c|c|c|c|}
\hline \multirow{2}{*}{$\begin{array}{l}\text { Wavenumber } \\
\left(\mathrm{cm}^{-1}\right)\end{array}$} & \multicolumn{2}{|l|}{ Camomile extract (CE) } & \multicolumn{2}{|l|}{$\mathrm{AgNPs} / \mathrm{CE}$} \\
\hline & Bond/stretching & Functional group & Bond/stretching & Functional group \\
\hline 535 & $\mathrm{C}-\mathrm{N}$ stretch & $\begin{array}{l}\text { Secondary amines and } \\
\text { amides }\end{array}$ & $\mathrm{C}-\mathrm{N}$ stretch & $\begin{array}{l}\text { Secondary amines and } \\
\text { amides }\end{array}$ \\
\hline 620 & $\mathrm{C}-\mathrm{N}$ stretch & $\begin{array}{l}\text { Secondary amines and } \\
\text { amides }\end{array}$ & $\mathrm{C}-\mathrm{N}$ stretch & $\begin{array}{l}\text { Secondary amines and } \\
\text { amides }\end{array}$ \\
\hline 1053 & $\mathrm{C}-\mathrm{O}-\mathrm{C}$ stretch & $\begin{array}{l}\text { Aromatic ethers and } \\
\text { polysaccharides }\end{array}$ & $\mathrm{C}-\mathrm{O}-\mathrm{C}$ stretch & $\begin{array}{l}\text { Aromatic ethers and } \\
\text { polysaccharides }\end{array}$ \\
\hline 1109 & $-\mathrm{C}-\mathrm{O}$ & Terpenoids, flavones & Not present & \\
\hline 1250 & $\begin{array}{l}\mathrm{C}-\mathrm{H} \text { stretch and } \mathrm{O}-\mathrm{H} \text { deform. of } \\
\text { carboxyl groups and bending of } \\
\mathrm{N}-\mathrm{H} \text { bond }\end{array}$ & Amide III & $\begin{array}{l}\mathrm{C}-\mathrm{H} \text { stretch and } \mathrm{O}-\mathrm{H} \text { deform. of } \\
\text { carboxyl groups and bending of } \\
\mathrm{N}-\mathrm{H} \text { bond }\end{array}$ & Amide III \\
\hline 1375 & $\mathrm{C}-\mathrm{N}$ stretch & Aromatic amines I, II & $\mathrm{C}-\mathrm{N}$ stretch & Aromatic amines I, II \\
\hline 1516 & $\mathrm{C}=\mathrm{C}$ & $\begin{array}{l}\text { Aromatic chain in } \\
\text { carboxylic acids } \\
\text { from patulein }\end{array}$ & $\mathrm{C}=\mathrm{C}$ & $\begin{array}{l}\text { Aromatic chain in } \\
\text { carboxylic acids } \\
\text { from patulein }\end{array}$ \\
\hline 1628 & $\mathrm{C}=\mathrm{O}$ bond & Luteolin & $\mathrm{C}=\mathrm{O}$ bond & Luteolin \\
\hline 1737 & $\mathrm{C}=\mathrm{O}$ bond & Luteolin & $\mathrm{C}=\mathrm{O}$ bond & Luteolin \\
\hline 2827 & $\mathrm{C}-\mathrm{H}$ stretch & $\begin{array}{l}\text { Aliphatic group of } \\
\text { glucosides }\end{array}$ & $\mathrm{C}-\mathrm{H}$ stretch & $\begin{array}{l}\text { Aliphatic group of } \\
\text { glucosides }\end{array}$ \\
\hline 2926 & $\mathrm{C}-\mathrm{H}$ stretch & $\begin{array}{l}\text { Aliphatic group of } \\
\text { glucosides }\end{array}$ & $\mathrm{C}-\mathrm{H}$ stretch & $\begin{array}{l}\text { Aliphatic group of } \\
\text { glucosides }\end{array}$ \\
\hline 3400 & $\mathrm{O}-\mathrm{H}$ stretch and $\mathrm{N}-\mathrm{H}$ stretch & Phenols and amides & $\mathrm{O}-\mathrm{H}$ stretch and $\mathrm{N}-\mathrm{H}$ stretch & Phenols and amides \\
\hline
\end{tabular}

Fig. 4 UV-vis spectra for: CE (black) showing the two peaks corresponding to terpenoids, for $\mathrm{AgNPs} / \mathrm{CE}$ (red) and AgNPs/G (green)—only one peak from silver is visible (color figure online)

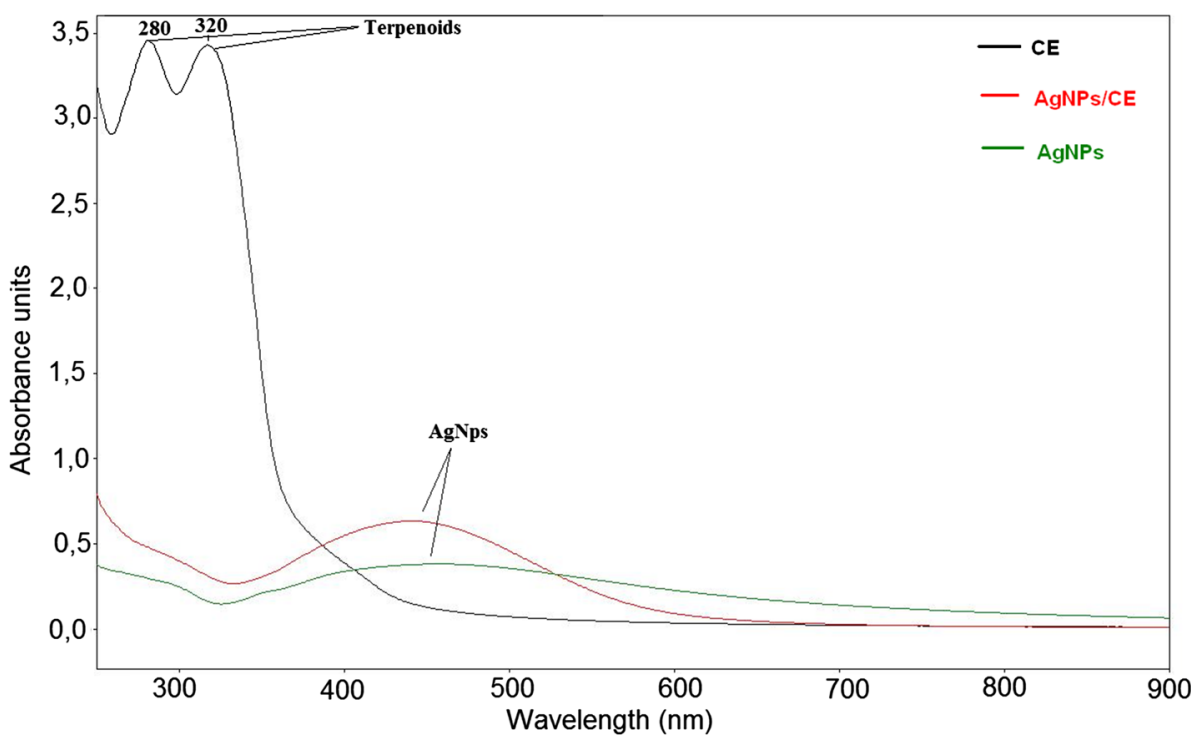

\section{Discussion}

STEM structural analyses of the camomile extract showed that it is composed of highly porous globules formed by aggregation and agglomeration processes, Fig. 2a, b. Hence, they have a very developed surface area, guaranteeing an easy attachment of the Ag NPs and making them a perfect support for the Ag nanoparticles. In the EDX maps, Fig. 2c, d, oxygen and phosphorus are detected. Both elements are expected to be present in camomile, as its chemical constituents include among others terpenoids, flavones flavonoids, apigenin and alpha-bisabolol. 

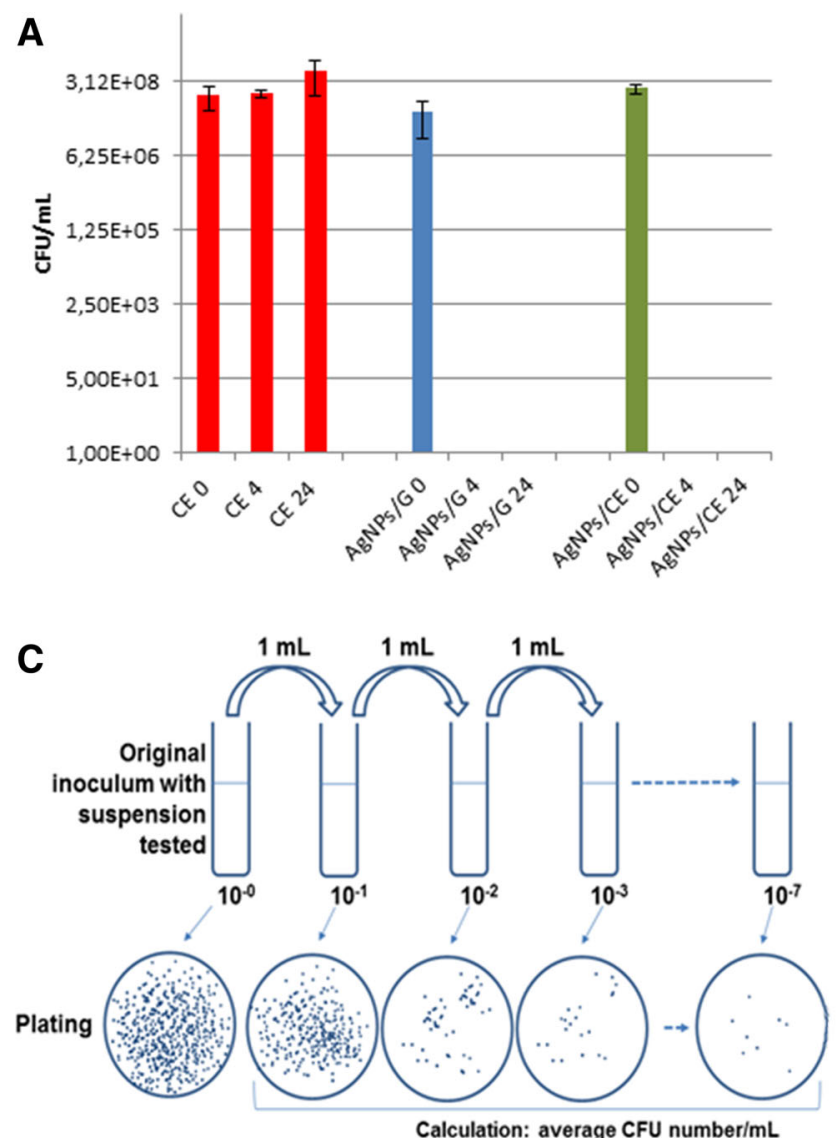

Fig. 5 a Antibacterial test of camomile extract (CE), plant extract with silver nanoparticles (AgNPs/CE) and pure nanoparticles synthesized with glucose (AgNPs/G) against $S$. aureus. b The percentage of
B
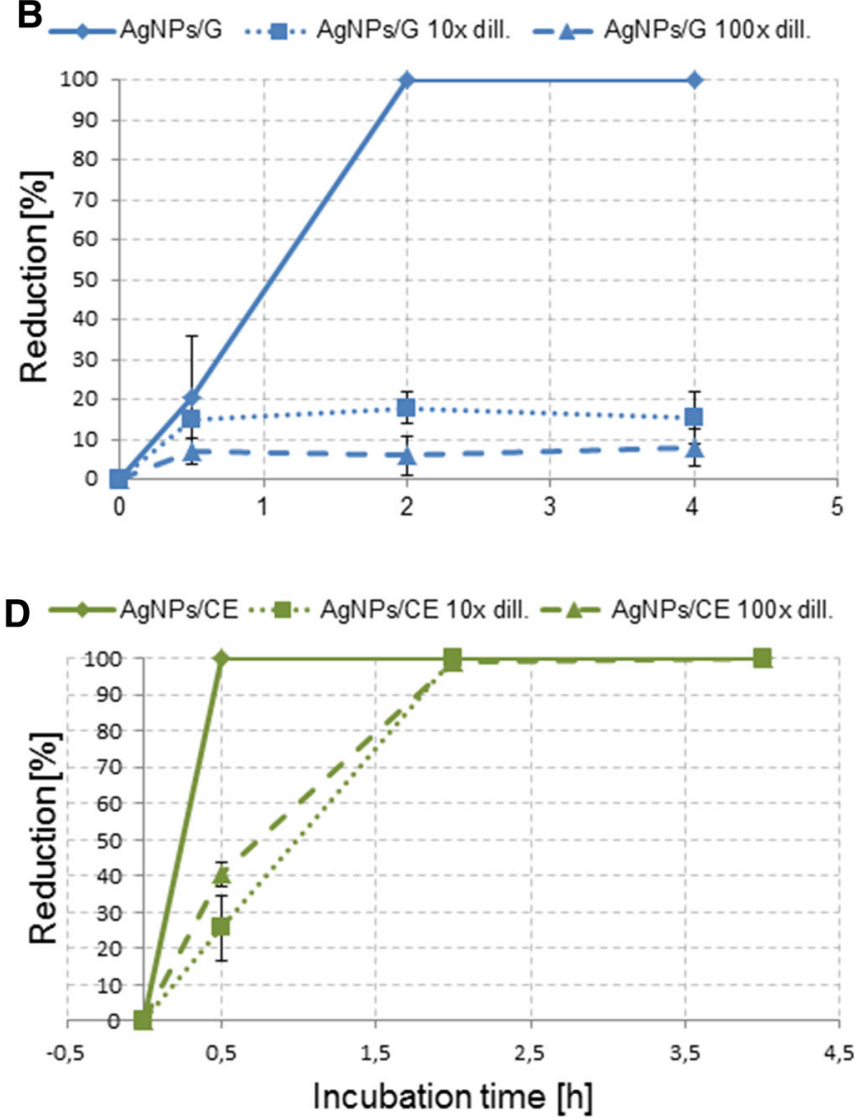

microorganism (S. aureus) reduction exposed to the tested nanosuspensions: AgNPs/G (above) and AgNPs/CE (below). c The flowchart for the evaluation of colony forming unit (CFU)
Fig. 6 The mean zone of inhibition against various bacteria strains using agar diffusion method. The wells contain: camomile extract synthesized silver nanoparticles (AgNPs/CE) - left side or pure nanoparticles (AgNPs/G) right side, respectively
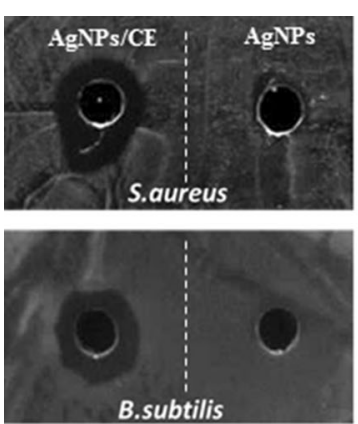

Indeed, all of these compounds are composed of hydrogen, oxygen and carbon. The latter element is also present as the support foil on the $\mathrm{Cu}$ grid, and is thus, detected by EDX as background in all the samples. Hydrogen is an element, which cannot be detected by EDX. Terpenoids in their chemical formula contain phosphorus additionally to $\mathrm{C}, \mathrm{H}$ and O, Fig. $2 \mathrm{~m}$. Therefore, it was decided to map phosphorous and oxygen.

The structural analysis of AgNPs/CE showed $\mathrm{Ag}$ nanoparticles located on globular structures, similar to the ones observed in pure camomile. This morphology proves

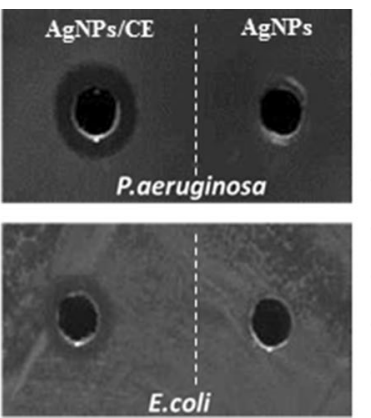

\begin{tabular}{|c|c|}
\hline Bacteria strain & $\begin{array}{c}\text { Averange diameter } \\
\text { of zone of } \\
\text { inhibitor [mm] }\end{array}$ \\
\hline S. aureus & $3.85 \pm 0.97$ \\
\hline$P$. aeruginosa & $3.25 \pm 0.65$ \\
\hline B. subtilis & $3.25 \pm 0.50$ \\
\hline E. coli & $2.94 \pm 0.73$ \\
\hline
\end{tabular}

that indeed the $\mathrm{Ag}$ nanoparticles were reduced in the camomile extract. The Ag particles are uniformly distributed on the camomile globules, making their very large surface available for antibacterial activity. Terpenoids are believed to be the surface-active molecules that stabilize nanoparticles [41] preventing the Ag NPs from agglomeration. Surprisingly, phosphorus is detected in the EDX maps on the Ag particles rather than, as expected, on the camomile globules, Fig. 2h. This might be explained combing this observation with the FTIR results showing the involvement of terpenoids in the reduction of $\mathrm{Ag}^{+}$ions. 


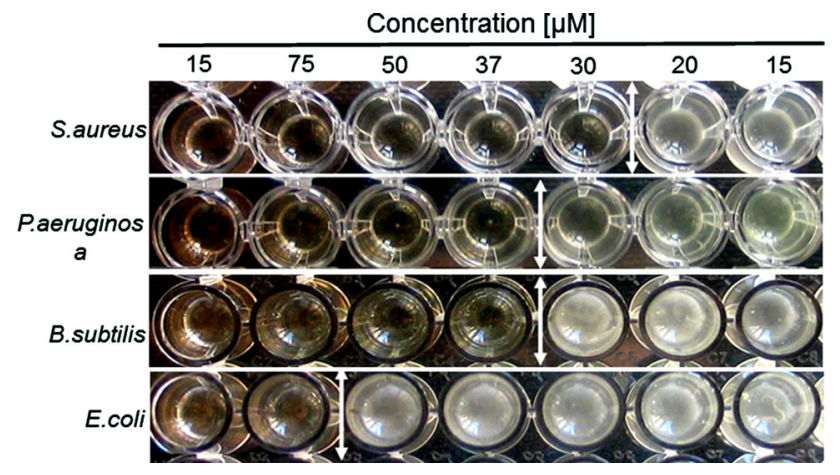

Fig. 7 MICs of nanomaterials against bacterial strains. Different concentrations of nanosolutions, were estimated from the concentration of silver nitrate, which was used as precursor, and were exposed to $S$. aureus, $P$. aeruginosa, B. subtilis and E. coli. White bars on the photograph denote the MICs for this experiment

The involvement of phenolics, proteins, terpenoids and other reducing agents in the synthesis of metal nanoparticles has been speculated [37]. The reduction from $\mathrm{Ag}^{+}$ions to silver nanoparticles $\left(\mathrm{Ag}^{0}\right)$ with terpenoids may involve the conversion of $\mathrm{C}-\mathrm{O}$ group of the terpenes to $-\mathrm{C}-\mathrm{O}$ group [40]. It is also possible that the terpenoids play a role in the reduction of metal ions by oxidation of aldehydic groups in the molecules to carboxylic acids [37]. The experimentally observed presence of phosphorus on the surface of $\mathrm{Ag}$ in the EDX maps strongly suggests that indeed terpenoids could be adsorbed on the surface of metal nanoparticles, possibly by interaction through carbonyl groups or $\pi$-electrons in the absence of other strong ligating agents in sufficient concentration. Moreover, the peak visible in the FTIR spectrum of CE at $1109 \mathrm{~cm}^{-1}$ and the double peak in the UV-vis spectrum of CE at 280 and $320 \mathrm{~nm}$ corresponding to $-\mathrm{C}-\mathrm{O}$ group in terpenoids disappear in the FTIR and UV-vis spectra of the AgNPs/CE, respectively [35]. The measurements performed by these three experimental techniques confirmed that terpenoids are indeed adsorbed on the AgNPs surface preventing their agglomeration. The difference in intensity and width of the peaks for $\mathrm{AgNPs} / \mathrm{CE}$ and $\mathrm{AgNPs} / \mathrm{G}$ spectra is directly related to the size of the Ag particles, which are more than six times larger in pure AgNPs suspension compared to the $\mathrm{AgNPs} / \mathrm{CE}$.

The above-discussed results strongly suggest that terpenoids act as capping agents during synthesis of $\mathrm{Ag}$ nanoparticles. Capping agents are ionic species, small molecules, or macromolecules that can selectively bind to different types of facets on a nanocrystal to change their specific surface free energies and in this way their area proportions [46]. Introducing a capping agent into a reaction solution, the type of facet stabilized by the capping agent will exhibit a lower specific surface free energy. This will result in the formation of nanocrystals with a shape favoring a certain type of facet, as the capping agent chemisorbed on a facet will prevent the deposition of atoms onto this facet [46, Fig. 5]. The AgNPs/CE on the STEM image, Fig. 2f, have an octahedron-like shape. Thus, camomile terpenoids seem to act as a capping agent for $\{111\}$ facets promoting the nanoparticle growth along the $<100>$ directions. The proportion of the $\mathrm{Ag}\{100\}$ facets is reduced during growth leading consequently to the formation of octahedrons enclosed only by $\{111\}$ facets.

The test of survival of $S$. aureus bacteria cells exposed to the tested suspensions lead to the conclusion, that both $\mathrm{Ag}$ containing nanosuspensions are extremely toxic to bacteria. Other authors studied $\mathrm{Ag}$ nanoparticles synthesized with camomile exposed to E. coli strain, showing high toxicity of Ag on bacteria [42,43] which is consistent with our results. To estimate the antibacterial activity of our nanosuspensions the difference in toxicity between CE, AgNPs/Ce and AgNPs/G was verified. Among the tested suspensions, only pure extract did not exhibit any bactericidal effect. This is consistent with the data obtained by Kaviya, who synthesized silver NPs using citrus sinensis peel extract, instead of the camomile extract [43]. Ghosh et all postulated that if silver nanoparticles and some natural metabolite have bactericidal potential, these components could be utilized together. Their synergistic action should enhance the antibacterial effect [44]. This effect was compared for pure AgNPs/G and AgNPs/CE suspensions, depending on their concentration.

The results of the cytotoxicity study show that the antibacterial activity of AgNPs/CE is much more efficient against pathogenic bacteria than the one of AgNPs/G. In comparison to $\mathrm{AgNPs} / \mathrm{CE}$, the smaller antibacterial effect (observed in all antibacterial assays) of pure $\mathrm{AgNPs} / \mathrm{G}$ is due to their large size combined with strong agglomeration. This suggests that the high microbial activity of AgNPs/CE originates from the synergistic effect of substances such as phenolics and flavonoids present in the camomile extract and the Ag particles. Indeed, Gogoi and co-authors obtained similar bactericidal results using green synthesis of silver nanoparticles based on alcoholic flower extract of Nyctanthes arbortristis [44, 45]. This hypothesis is confirmed also by the MIC test as well as zone of inhibition Fig. 7. In both cases, AgNPs/CE suspension clearly affected the bacterial growth.

Electron microscopy analysis of the AgNPs/CE showed that the Ag nanoparticles have sizes between 2 and $12 \mathrm{~nm}$ and are well dispersed on the globular camomile support, prohibiting their agglomeration. This dispersion combined with the small size allows these $\mathrm{Ag}$ particles to exploit their entire active surface-the smaller the particle the higher its activity. The synthesis of $\mathrm{Ag}$ in camomile extract containing terpenoids allowed preventing agglomeration of the $\mathrm{Ag}$ particles, which is a common problem for nanosized 
particles reducing their activity. The AgNPs/G synthesized without camomile is agglomerated, Fig. 2 column III, what reduces considerably their active surface, which would explain their lower antibacterial activity compared to the AgNPs/CE. These findings clearly demonstrate that it is indeed possible to have a much greener way to synthesize AgNPs without compromising their antibacterial properties. Thus, plant extracts may prove to be a good alternative to obtain such NPs with improved antibacterial and antiviral properties for antibacterial applications.

\section{Conclusions}

Structural and antibacterial properties of camomile extract synthesized Ag nanoparticles were assessed and compared with the performance of pure camomile extract and pure Ag nanoparticles synthesized with glucose. Indeed, it was experimentally proven that AgNPs synthesized with $\mathrm{CE}$ are uniformly distributed on porous globular structures constituting the camomile support. The dispersion of these AgNPs combined with their size between 2 and $12 \mathrm{~nm}$ allows them to use their whole active surface, which is thus much larger than the one of pure AgNPs/G with sizes exceeding $50 \mathrm{~nm}$. In the AgNPs/CE suspension, the EDX maps of phosphorus, a component of terpenoids, showing its distribution on the $\mathrm{Ag}$ particles, combined with the FTIR and UV-vis spectra, where the peak originating from terpenoids disappears, leads to the conclusion that terpenoids play an important role in the reduction of $\mathrm{Ag}^{+}$ions to $\mathrm{Ag}$ metallic nanoparticles. Moreover, terpenoids are most probably adsorbed on the metal surface as surfaceactive molecules, preventing the AgNPs from agglomeration. The antibacterial activity of the three suspensions was compared. The CE sample did not show any bactericidal effect. Conversely, both solutions containing AgNPs showed an antibacterial performance. In the \% of reduction, zone of inhibition and minimum inhibitory concentration tests, the AgNPs/CE solution performed outstandingly the best, killing all bacteria strains in short time. This study shows that camomile, with its porous globular structure constitutes a perfect support for AgNPs offering simultaneously a synergistic antibacterial effect. Moreover, the used green way of synthesis of AgNPs/CE allows reducing the environmental impact, as camomile extract is non-toxic to living things and the environment.

Acknowledgments The use of the FEI Tecnai Osiris TEM instrument located at the Facility for Electron Microscopy and Sample Preparation of the University of Rzeszow is acknowledged. The authors would like to thank Professor Andrzej Kowal for fruitful discussions and for inspiring us with the bright idea of using camomile for AgNPs synthesis. MSc. Renata Wojnarowska is acknowledged for her help in UV-vis measurements and MSc. Angelika
Mysliwiec for her help in synthesis of the nanoparticles. Project UDA-RPPK.01.03.00-18-052/12-00 is acknowledged. The authors would like to thank Mr. M. Sterczewski from A.P. Instruments for particle size measurements using a Zetasizer Nano ZS instrument from Malvern.

Open Access This article is distributed under the terms of the Creative Commons Attribution 4.0 International License (http://crea tivecommons.org/licenses/by/4.0/), which permits unrestricted use, distribution, and reproduction in any medium, provided you give appropriate credit to the original author(s) and the source, provide a link to the Creative Commons license, and indicate if changes were made.

\section{References}

1. Dobrovolskaia MA, McNeil SE (2007) Immunological properties of engineered nanomaterials. Nat Nanotechnol 2:469-478

2. Liu L, Yang J, Xie J, Luo Z, Jiang J, Yang Y, Shaomin L (2013) The potent properties of cell penetrating peptide-conjugated silver nanoparticles with excellent selectivity for gram-positive bacteria over erythrocytes. Nanoscale 5:3834-3840

3. Tran QH, Nguyen VQ, Le AT (2013) Silver nanoparticles: synthesis, properties, toxicology, applications and perspectives. Adv Nat Sci Nanosci Nanotechnol 9:033001

4. Mohammadzadeh R (2012) Skin infection management using novel antibacterial agents. Adv Pharm Bull 3(1):247-248

5. Goldsmith BR, Mitala JJ, Josue JJ, Castro A, Lerner MB, Bayburt $\mathrm{TH}$, Khamis SM, Jones RA, Brand JG, Sligar SG, Luetje ChW, Gelperin A, Rhodes PA, Discher BM, Johnson ATCh (2011) Biomimetic chemical sensors using nanoelectronic readout of olfactory receptor proteins ACS. NANO 5(7):5408-5416

6. Kotthaus S, Gunther GH, Hang R, Schafer H (1995) Rapid green synthesis of silver nanoparticles from Chrysanthemum indicum $\mathrm{L}$. and its antibacterial and cytotoxic effects: an in vitro study. IEEE Trans Compon Packag Manuf Technol 9:379-388

7. Kim KJ, Sung WS, Suh BK, Moon SK, Choi JS, Kim JG, Lee DG (2009) Antifungal activity and mode of action of silver nanoparticles on Candida albicans. Biometals 22(2):235-242

8. Chowdhury IH, Ghosh S, Roy M, Naskar MK (2015) Green synthesis of water-dispersible silver nanoparticles at room temperature using green carambola (star fruit) extract. J Sol Gel Sci Technol 73:199

9. Silver S (2007) Bacterial silver resistance: molecular biology and uses and misuses of silver compounds. FEMS Microb Rev 27:341-353

10. Esumi K, Tano T, Torigoe K, Meguro K (1990) Preparation and characterization of bimetallic palladium-copper colloids by thermal decomposition of their acetate compounds in organic solvents. Chem Mater 2(5):564-567

11. Pastoriza-Santos I, Liz-Marzan LM (2002) Preparation of PVDprotected metal nanoparticles in DMF. Langmuir 18:2888-2894

12. Gardea-Torresdey JL, Gomez E, Peralta-Videa J, Parsons JG, Troiani HE, Jose-Yacaman M (2003) Alfalfa sprouts: a natural source for the synthesis of silver nanoparticles. Langmuir 19:1357-1361

13. Sivaraman SK, Elango I, Kumar SA (2009) green protocol for room temperature synthesis of silver nanoparticles in seconds. Curr Sci 97:1055-1059

14. Grover A, Yadav S, Vats V (2002) Medicinal plants of India with anti-diabetic potential. J Ethnopharmacol 81(1):81-100

15. Ayyanar BM, Ignacimuthu S (2011) Ethnobotanical survey of medicinal plants commonly used by Kani tribals in Tirunelveli hills of Western Ghats. India J Ethnopharmacol 134(3):851-864 
16. Bulent U, Turkdemir MH, Cicek A, Mete A (2015) Role of irradiation in the green synthesis of silver nanoparticles mediated by fig (Ficus carica) leaf extract. Spectrochim Acta Part A Mol Biomol Spectrosc 135:153-161

17. Shankar SS, Rai A, Ankamwar B, Singh A, Ahmad A, Sastry M (2004) Biological synthesis of triangular gold nanoprisms. Nat Mater 3(7):482-488

18. Leela A, Vivekanandan M (2008) Tapping the unexploited plant resources for the synthesis of silver nanoparticles. Afr J Biotechnol 7(17):3162-3165

19. Augustine R, Kalarikkal N, Thomas SA (2014) facile and rapid method for the black pepper leaf mediated green synthesis of silver nanoparticles and the study. Appl Nanosci 4:809-818

20. Rashidipour M, Heydari R (2014) Biosynthesis of silver nanoparticles using extract of olive leaf: synthesis and in vitro cytotoxic effect on MCF-7 cells. J Nanostruct Chem 4:112

21. Sathishkumar MK, Sneha KSW, Won SW, Cho CW, Kim S, Yun YS (2009) Cinnamon zeylanicum bark extract and powder mediated green synthesis of nano-crystalline silver particles and its bactericidal activity. Colloids Surf B Biointerfaces 73(2):332-338

22. Hui X, Wang L, Su H, Gu L, Han T, Meng F, Liu Ch (2015) Make good use of food wastes: green synthesis of highly stabilized silver nanoparticles from grape seed extract and their activity. Food Biophys 10(1):12-18

23. Jaina D, Daimab HK, Kachhwahaa S, Kothari SL (2009) Synthesis of plant-mediated silver nanoparticles using papaya fruit extract and evaluation of their anti microbial activities. Dig $\mathbf{J}$ Nanomater Biostruct 4(4):723-727

24. Astin JD, Pelletier KR, Marie A, Haskell WL (2000) Complementary and alternative medicine use among elderly persons. One year analysis of Blue Shield medicare supplement. J Gerontol A Biol Sci Med 55:M4-M9

25. Ruszynska H, Borysewicz-Lewicka M, Marciniecka-Hedzelek J, Kurhanska-Flisykowska A, Surdacka A (1986) Evaluation of therapeutic properties of a chamomile-containing toothpaste. Czasopismo Stomatologiczne 39:485-490

26. Fidler P, Loprinzi CL, O'Fallon JR (1996) Prospective evaluation of a chamomile mouthwash for prevention of 5-FU-induced oral mucositis. Cancer 77:522-525

27. Srivastava JK, Shankar E, Gupta S (2010) Chamomile: a herbal medicine of the past with bright future. Mol Med Rep 3(6):895-901

28. Srivastava JK, Gupta S (2007) Antiproliferative and apoptotic effects of chamomile extract in various human cancer cells. J Agric Food Chem 55:9470-9478

29. Kato A, Minoshima Y, Yamamoto J, Adachi I, Watson AA, Nash RJ (2008) Protective effects of dietary chamomile tea on diabetic complications. J Agric Food Chem 56:8206-8211

30. Clinical and Laboratory Standards Institute (2015) Performance standards for antimicrobial disk susceptibility tests; Approved Standard-Twelfth edn. CLSI Document: M02-A12, Wayne, PA

31. Martinez-Gutierrez F, Olive PL, Orrantia E, Nino E, Sanchez EM, Ruiz F, Bach F, Av-Gay Y (2010) Synthesis, characterization, and evaluation of antimicrobial and cytotoxic effect of silver and titanium nanoparticles. Nanomed Nanotechnol Biol Med 6(5):681-688
32. Paredes D, Ortiz C, Torres R (2014) Synthesis, characterization, and evaluation of antibacterial effect of $\mathrm{Ag}$ nanoparticles against Escherichia coli O157:H7 and methicillin-resistant Staphylococcus aureus (MRSA). Int J Nanomed 3(9):1717-1729

33. Nabikhan A, Kandasamy K, Raj A, Alikunhi NM (2010) Synthesis of silver nanoparticles by callus and leaf extracts from saltmarsh plant, Sesuvium portulacastrum L. Colloids Surf B Biointerfaces 79:488-493

34. Szymczycha-Madeja A, Welna M, Zyrnicki W (2013) Multielement analysis, bioavailability and fractionation of herbal tea products. J Braz Chem Soc 24(5):777-787

35. Huang J, Li Q, Sun D, Lu Y, Su Y, Yang Wang H, Wang Y, Shao W, He N, Hong J (2007) Biosynthesis of silver and gold nanoparticles by novel sundried Cinnamomum camphora leaf. Nanotechnology 18:105104-105115

36. Ibrahim M, Alaam M, El-Haes H, Jalbout AF (2006) Analysis of the structure and vibrational spectra of glucose and fructose. Eclet Quim 31(3):15-21

37. Shankar SS, Rai A, Ahmad A, Sastry M (2004) Rapid synthesis of $\mathrm{Au}, \mathrm{Ag}$, and bimetallic $\mathrm{Au}$ core- $\mathrm{Ag}$ shell nanoparticles using neem (Azadirachta indica) leaf broth. J Colloid Interface Sci 275:496-502

38. Kumar KA, Choudhary RK, Joshi B, Ramya V, Sahithi V, Veena $P$ (2011) Determination of antibacterial, antifungal activity and chemical composition of essential oil portion of unani formulation kulzam. Int J Green Pharm 5:28-33

39. Colegate SM, Molyneux RJ (2007) Bioactive natural products: detection, isolation and structural determination. CRC Press, Boca Raton

40. Chitte HK, Bhat NV, Karmakar NS, Kothari BC, Shinde GN (2012) Tuning of refractive index of poly(vinyl alcohol): effect of embedding $\mathrm{Cu}$ and $\mathrm{Ag}$ nanoparticles tuning of refractive index of poly(vinyl alcohol): effect of embedding $\mathrm{Cu}$ and $\mathrm{Ag}$ nanoparticles. World J Nanosci Eng 2:19-24

41. Dubey SP, Lahtinen M, Sarkka H, Sillanpaa M (2010) Bioprospective of Sorbus aucuparia leaf extract in development of silver and gold nanocolloids. Colloids Surf B Biointerfaces 80:26-33

42. Song JY, Jang HK, Kim BS (2009) Biological synthesis of gold nanoparticles using Magnolia kobus and Diopyros kaki leaf extracts. Process Biochem 44:1133-1138

43. Kaviya S, Santhanalakshmi J, Viswanathan B, Muthumary J, Srinivasan K (2011) Biosynthesis of silver nanoparticles using citrus sinensis peel extract and its antibacterial activity. Spectrochim Acta Part A Mol Biomol Spectrosc 79(3):594-598

44. Ghosh IN, Patil SD, Sharma TK, Srivastava SK, Pathania R, Navani NK (2013) Synergistic action of cinnamaldehyde with silver nanoparticles against spore-forming bacteria: a case for judicious use of silver nanoparticles for antibacterial applications. Int J Nanomed 8:4721-4731

45. Gogoi N, Babu PJ, MahantaC Bora U (2015) Green synthesis and characterization of silver nanoparticles using alcoholic flower extract of Nyctanthes arbortristis and in vitro investigation of their antibacterial and cytotoxic activities. Mater Sci Eng C Mater Biol Appl 46:463-469

46. Xia Y, Xia X, Peng HC (2015) Shape-controlled synthesis of colloidal metal nanocrystals: thermodynamic versus kinetic products. J Am Chem Soc 137:7947-7966 